\title{
Flock Growth Kinetics for Flocculation in an Agitated Tank
}

\author{
R. Sulc, O. Svačina
}

\begin{abstract}
Flock growth kinetics was investigated in baffled tank agitated by a Rushton turbine at mixing intensity $40 \mathrm{~W} / \mathrm{m}^{3}$ and kaolin concentration $0.44 \mathrm{~g} / \mathrm{l}$. The tests were carried out with a model wastewater (a suspension of tap water and kaolin). The model wastewater was flocculated with organic Sokoflok 56 A flocculant (solution $0.1 \%$ wt.). The flock size and flock shape were investigated by image analysis. A simple semiempirical generalized correlation for flock growth kinetics was proposed, and was used for data treatment. The flock shape was characterized by fractal dimension $D_{f 2}$. Using the statistical hypothesis test, the fractal dimension was found to be independent of flocculation time, and the value $D_{f 2}=1.442 \pm 0.125$ was determined as the average value for the given conditions.
\end{abstract}

Keywords: flocculation, flock growth, flock size, mixing, Rushton turbine, kaolin slurry.

\section{Introduction}

Flocculation is one of the most important operations in solid - liquid separation processes in water supply and wastewater treatment. The purpose of flocculation is to transform fine particles into coarse aggregates - flocks that will eventually settle - in order to achieve efficient separation.

The properties of separated particles have a major effect on the separation process and on separation efficiency in a solid - liquid system. The solid particles in a common solid - liquid system are compact and are regular in shape, and their size does not change during the process. The size of these particles is usually sufficiently described by the diameter or by some equivalent diameter.

The flocks that are generated are often porous and are irregular in shape, which complicates the flocculation process design. Flock properties such as size, density and porosity affect the separation process and its efficiency.

The aim of this work is to propose a simple semiempirical generalized correlation for flock growth kinetics and to verify the proposed model experimentally.

\section{Generalized correlation for flock growth kinetics}

Turbidity measurement has been used and recommended for flocculation performance assessment in routine control in industry. Flocculation efficiency has frequently been expressed as the rate of turbidity removal:

$$
Z_{e}^{*}\left(t_{F}\right)=\frac{Z_{e}\left(t_{F}\right)}{Z_{0}}=\frac{Z_{0}-Z_{r}\left(t_{F}\right)}{Z_{0}}=1-Z_{r}^{*}\left(t_{F}\right)
$$

where $Z_{e}^{*}$ is turbidity removal degree, $Z_{r}^{*}$ is residual turbidity degree, $Z_{0}$ is turbidity of a suspension before the beginning of flocculation, $Z_{e}$ is eliminated turbidity due to flocculation, $Z_{r}$ is residual turbidity of clarified water after flock separation, and $t_{F}$ is flocculation time.

Sulc [1] found that flocculation kinetics expressed as the dependence of the residual turbidity rate on the flocculation time can be expressed by a simple formula, taking into account flock breaking:

$$
Z_{r}^{*}=A_{Z r^{*}} \cdot \log ^{2}\left(t_{F}^{*}\right)+B_{Z r^{*}} \cdot \log \left(t_{F}^{*}\right)+C_{Z r^{*}}
$$

where $Z_{r}^{*}$ is residual turbidity degree, $t_{F}^{*}$ is dimensionless flocculation time, and $A_{Z r^{*}}, B_{Z r^{*}}, C_{Z r^{*}}$ are the model parameters. For flocculation taking place in an agitated tank, Sulc and Ditl [2] recommend dimensionless flocculation time $t_{F}^{*}$ given by:

$$
t_{F}^{*}=n \cdot t_{F}
$$

where $t_{F}$ is flocculation time, and $n$ is impeller rotational speed. The proposed definition of dimensionless flocculation takes this into account due to the characteristic time choice. The chosen characteristic time, $t_{\text {char }} \propto 1 / n$, is proportional to the number of liquid passages through an impeller.

Based on Eq. (2) Šulc [1], Sulc and Ditl [3] have proposed a generalized correlation for flocculation kinetics in an agitated tank that takes into account flock breaking, as follows:

$$
\Delta Z_{r}^{*}=A_{Z r^{*}}^{*} \cdot\left(\Delta\left[n t_{F}\right]_{\log }^{*}\right)^{2}
$$

where

$$
\begin{aligned}
\Delta Z_{r}^{*} & =\frac{Z_{r}^{*}-Z_{r_{\min }}^{*}}{Z_{r_{\min }}^{*}} \\
\Delta\left[n t_{F}\right]_{\log }^{*} & =\frac{\log \left(n t_{F}\right)-\log \left(\left[n t_{F}\right]_{\min }\right)}{\log \left(\left[n t_{F}\right]_{\min }\right)},
\end{aligned}
$$

where $Z_{r \min }^{*}$ is minimal residual turbidity degree achieved at time $\left[n t_{F}\right]_{\min },\left[n t_{F}\right]_{\min }$ is the dimensionless flocculation time in which $Z_{r \min }^{*}$ can be achieved, 
$A^{*}$ is the residual turbidity shift coefficient, $t_{F}$ is the flocculation time, and $n$ is impeller rotational speed.

According to Lambert's law, the turbidity depends on the cross-sectional area of the flock $\sigma$ and flock concentration $N_{p}$, as follows:

$$
Z_{r} \propto N_{p} \cdot \sigma
$$

Assuming that the cross-sectional area of flock $\sigma$ is proportional to flock size $d_{f}$

$$
\sigma \propto d_{f}^{2}
$$

and particle/flock mass conservation must be fulfilled at any time, flock concentration $N_{p}$ can be expressed as follows:

$$
N_{p} \cdot d_{f}^{3} \propto \text { const. }
$$

Using Eqs. (7), (8) and (9), the dependence of flock size on flocculation time can be given by a simple formula taking into account flock breaking:

$$
\left(1 / d_{f}\right)=A_{f} \cdot \log ^{2}\left(n t_{F}\right)+B_{f} \cdot \log \left(n t_{F}\right)+C_{f}
$$

where $\left(1 / d_{f}\right)$ is reciprocal flock size, $n t_{F}$ is dimensionless flocculation time, and $A_{f}, B_{f}, C_{f}$ are the model parameters. Assuming that the minimum residual turbidity degree corresponds to the maximum flock size, the dimensionless model variable $\Delta Z_{r}^{*}$ can be rewritten as follows:

$$
\begin{aligned}
& \Delta Z_{r}^{*}=\frac{Z_{r}^{*}-Z_{r_{\min }}^{*}}{Z_{r_{\min }}^{*}}=\frac{Z_{r}-Z_{r_{\min }}}{Z_{r_{\min }}} \propto \\
& \frac{\frac{N_{f}}{N_{f_{\max }}} \cdot d_{f}^{2}-d_{f_{\max }}^{2}}{d_{f_{\max }}^{2}}=\frac{\left(1 / d_{f}\right)-\left(1 / d_{f_{\max }}\right)}{\left(1 / d_{f_{\max }}\right)}
\end{aligned}
$$

where $d_{f}$ is flock size and $d_{f \max }$ is maximal flock size.

Then the generalized correlation for flock growth kinetics that takes into account flock breaking can be derived as follows:

$$
\Delta\left(1 / d_{f}\right)^{*}=A_{f}^{*} \cdot\left(\Delta\left[n t_{F}\right]_{\log }^{*}\right)^{2}
$$

rewritten

$$
\frac{d_{f_{\max }}}{d_{f}}=1+A_{f}^{*} \cdot\left(\Delta\left[n t_{F}\right]_{\log }^{*}\right)^{2}
$$

where

$$
\begin{aligned}
\Delta\left(1 / d_{f}\right)^{*} & =\frac{\left(1 / d_{f}\right)-\left(1 / d_{f_{\max }}\right)}{\left(1 / d_{f_{\max }}\right)}, \\
A_{f}^{*} & =\frac{B_{f}^{2}}{4 \cdot A_{f} \cdot C_{f}-B_{f}^{2}},
\end{aligned}
$$

where $d_{f_{\max }}$ is the maximum flock size reached at time $\left[n t_{F}\right]_{\max },\left[n t_{F}\right]_{\max }$ is the dimensionless flocculation time in which $d_{f_{\max }}$ can be achieved, $\Delta\left[n t_{F}\right]_{\log }^{*}$ is the variable defined by Eq. (6), and $A_{f}, B_{f}, C_{f}$ are parameters of Eq. (10).

The generalized correlation parameters $d_{f_{\max }}$, $\left[n t_{F}\right]_{\max }$ and $A_{f}^{*}$ depend generally on the flocculation process conditions, e.g. mixing intensity and flocculation dosage.

\section{Model evaluation}

The proposed generalized correlation was tested on the published experimental data by Kilander et al. [4]. Kilander et al. [4] investigated the local flock size distributions in square tanks of different sizes (5, 7.3, 28 and $560 \mathrm{l})$. The areas investigated in the 7.3 and $28 \mathrm{l}$ tanks were the upper left corner (noted UC), the lower left corner (noted LC), directly over the impeller (noted OI) and directly under the impeller (noted UI). In the 5 and $560 \mathrm{l}$ tanks, the areas LC, OI and UI were investigated. A suspension of buffered water and kaolinite clay was used as the model flocculation system. The tanks were agitated by a Lightnin A 310 hydro foil impeller. The 5, 7.3 and $28 \mathrm{l}$ tanks were operated at two specific energy inputs, $1.72 \mathrm{~W} / \mathrm{m}^{3}$ and $2.55 \mathrm{~W} / \mathrm{m}^{3}$, corresponding to average gradient velocity 41.2 and $50.4 \mathrm{~s}^{-1}$, respectively. The $560 \mathrm{l}$ tank was operated only at specific energy input $2.55 \mathrm{~W} / \mathrm{m}^{3}$. No model of flock growth kinetics was applied for data interpretation.

The data in the UC area for the $7.3 \mathrm{l}$ and $28 \mathrm{l}$ tanks at specific power input $1.72 \mathrm{~W} / \mathrm{m}^{3}$ were analyzed. A comparison of the experimental data and a generalized correlation are depicted in Fig. 1. The generalized correlation parameters fitted for the measured data are presented in Table 1.

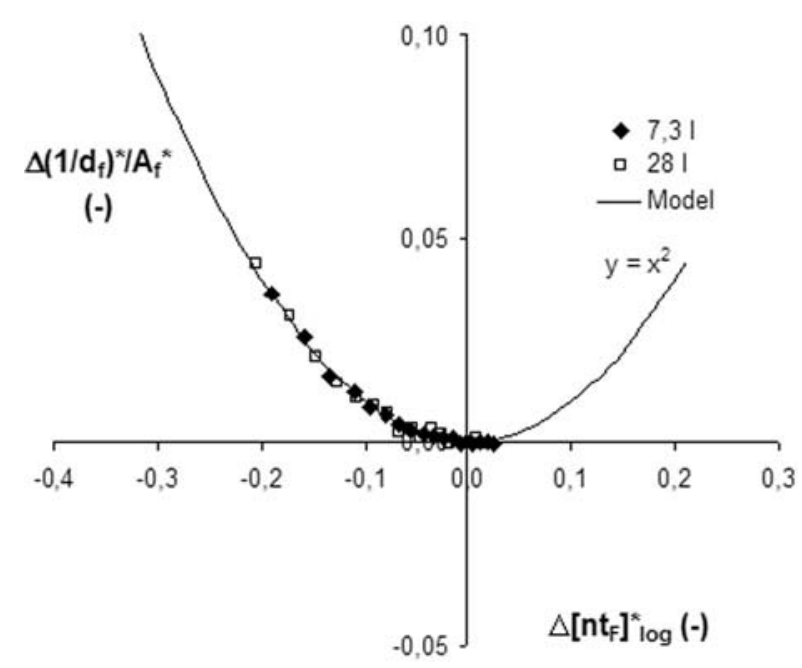

Fig. 1: Generalized correlation $\Delta\left(1 / d_{f}\right)^{*}=f\left(\Delta\left[n t_{F}\right]_{\log }^{*}\right)-$ Kilander et al. [4] 
Table 1: Generalized correlation parameters fitted - data Kilander et al. [4]

\begin{tabular}{|c|c|c|c|c|c|c|c|c|}
\hline$V$ & $\varepsilon_{V}$ & $n$ & {$\left[n t_{F}\right]_{\max }$} & $t_{F_{\max }}$ & $d_{f_{\max }}$ & $A_{f}^{*}$ & $I_{y x}$ & $\delta_{r_{\max }} / \delta_{r_{\text {ave }}} * 1$ \\
\hline$(\mathrm{L})$ & $\left(\mathrm{W} / \mathrm{m}^{3}\right)$ & $(\mathrm{rev} / \mathrm{min})$ & $(-)$ & $(\min )$ & $(\mathrm{mm})$ & $(-)$ & $(-)$ & $(\%)$ \\
\hline 7.3 & 1.72 & 199 & 6429 & 32.3 & 0.2314 & 39.108 & 0.9985 & $1.4 / 3.2^{* 2}$ \\
\hline 28 & 1.72 & 148 & 5217 & 35.3 & 0.1699 & 18.998 & 0.9978 & $1.6 / 4^{* 2}$ \\
\hline
\end{tabular}

*1 Relative error of flock size $d_{f}$ : maximum/average absolute value.

$* 2$ Data for $t_{F}=2.22 \mathrm{~min}$ and $t_{F}=3.89$ min were excluded.

\section{Experimental}

The flock growth kinetics was investigated in a baffled tank agitated by a Rushton turbine at mixing intensity $40 \mathrm{~W} / \mathrm{m}^{3}$ and kaolin concentration $0.44 \mathrm{~g} / \mathrm{l}$. The tests were carried out on the kaolin slurry model wastewater. The model wastewater was flocculated with organic Sokoflok 56A flocculant (solution $0.1 \%$ wt.). The flock size and its shape were investigated by image analysis. The proposed simple semiempirical generalized correlation for flock growth kinetics was used for data treatment. The fractal dimension of the flocks was also determined.

\subsection{Experimental apparatus}

The flocculation experiments were conducted in a fully baffled cylindrical vessel of diameter $D=150 \mathrm{~mm}$ with a flat bottom and 4 baffles per $90^{\circ}$, filled to height $H=D$ by a kaolin slurry model wastewater (tap water + kaolin particles). The vessel was agitated by a Rushton turbine (RT) of diameter $d=60 \mathrm{~mm}$ that was placed at an off-bottom clearance of $H_{2} / d=0.85$. Baffle width $B / D$ was 0.1 . The impeller motor and the Cole Parmer Servodyne model 50000-25 speed control unit were used in our experiments. The impeller speed was set up and the impeller power input value was calculated using the impeller power characteristics. The agitated vessel dimensions are shown in Fig. 2.

\section{Image analysis technique}

The flock size was determined using a non-intrusive optical method. The method is based on an analysis of the images obtained by a digital camera in a plane illuminated by a laser light. The method consists of three steps:

1. illumination of a plane in the tank with a laser light sheet (sometimes called a laser knife) in order to visualize the flocks,

2. a record of the images of the flocks, using a camera,

3. processing the images captured by image analysis software.

The illuminated plane is usually vertical and a camera is placed horizontally (e.g. Kilander et al. [4],
Kysela and Ditl [5, 6]). Kysela and Ditl [5, 6] used this technique for flocculation kinetics observation. They found that the application of this method is limited by the optical properties of the system. The required transparency limits the maximum particle concentration in the system. Therefore we do not observe the flock size during flocculation but we observe it during sedimentation, thus the limitation should be overcome. Therefore the laser illuminated plane is horizontal and perpendicular to the impeller axis. The scheme of the experimental apparatus for image analysis is shown in Fig. 2.

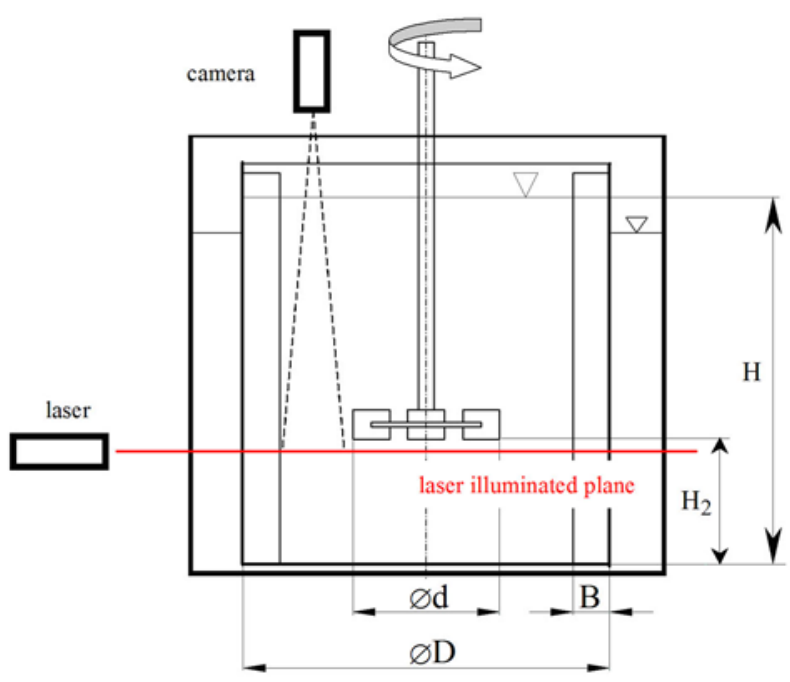

optical box

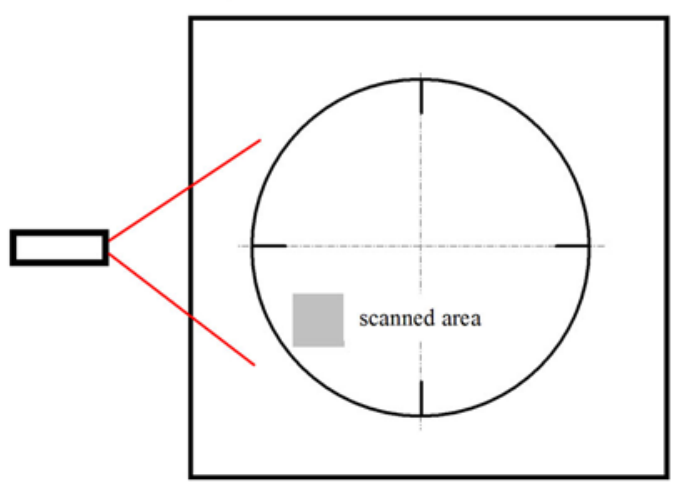

Fig. 2: Schema of the experimental apparatus for image analysis 
Table 2: Technical parameters

\begin{tabular}{|c|c|}
\hline Item & Specification \\
\hline Laser diode: & NT 57113, $30 \mathrm{~mW}$, wave length $635 \mathrm{~nm}$ (red light), Edmund Optics, Germany \\
\hline Diode optics: & optical projection head NT54-186, Projection Head Line, Edmund Optics, Germany \\
\hline Camera: & colour CMOS camera SILICON VIDEOßSI-SV9T001C, EPIX Inc., USA \\
\hline Camera optics: & objective 12VM1040ASIR 10-40 mm, TAMRON Inc., Japan \\
\hline $\begin{array}{l}\text { Image processing card } \\
\text { (so-called grabbing card): }\end{array}$ & PIXCI SI PCI Image Capture Board, EPIX Inc., USA \\
\hline Camera control software: & XCAP $\cap$, EPIX Inc., USA \\
\hline Operation software: & Linux CentOS version 5.2, Linux kernel 2.6 \\
\hline Software for image analysis: & SigmaScan Pro 5.0 \\
\hline
\end{tabular}

The agitated vessel was placed in an optical box (a water-filled rectangular box). The optical box reduces laser beam dispersion, and thus it improves the optical properties of the measuring system. The camera with the objective and laser diode are placed on the laboratory support stand. The technical parameters are presented in Table 2.

\subsection{Experimental procedure}

The maximum flock sizes formed during flocculation were measured for various flocculation times at mixing intensity $\varepsilon=40 \mathrm{~W} / \mathrm{m}^{3}$, constant flocculant dosage $D_{F}=2 \mathrm{ml} / \mathrm{l}$ and initial kaolin concentration $440 \mathrm{mg} / \mathrm{l}$. The flock sizes were measured during sedimentation. The experimental parameters are summarized in Table 3 .

Table 3: Experimental conditions

\begin{tabular}{|l|l|c|}
\hline \multicolumn{2}{|l|}{} & Kaolin concentration \\
\hline \multicolumn{2}{|l|}{ Parameter } & $c_{C 0}=0.44 \mathrm{~g} / \mathrm{l}$ \\
\hline$\varepsilon_{V}$ & $\left(\mathrm{~W} / \mathrm{m}^{3}\right)$ & 40 \\
\hline $\mathrm{n}$ & $(\mathrm{rev} / \mathrm{min})$ & 180 \\
\hline$t_{F}$ & $(\mathrm{~min})$ & $4 ; 6.66 ; 9.33 ; 13.33 ; 20$ \\
\hline$n t_{F}$ & $(-)$ & $720,1200,1680,2400,3600$ \\
\hline$D_{F}$ & $(\mathrm{ml} / \mathrm{l})$ & 2 \\
\hline No. of date & 5 \\
\hline
\end{tabular}

The experimental procedure was as follows:

\section{Calibration and experimental apparatus setting}

Before each flocculation experiment the calibration grid was placed in an illuminated plane and the camera was focused manually onto this calibration grid. Then the image of the calibration grid was recorded. For camera resolution $800 \times 800$ pixels, the scale 1 pixel $\propto 45 \mu \mathrm{m}$ was found for our images. This corresponds to a scanned area of $35 \mathrm{~mm} \times 35 \mathrm{~mm}$ (approx. $6 \%$ of the cross-section area of the tank). The scanned area was located in the middle of one quarter of the vessel, between the vessel wall and the impeller.

\section{Model wastewater preparation}

Kaolin slurry (a suspension of water and kaolin particles (18672 Kaolin powder finest Riedel-de Haen)) was used as a model system. The solid fraction of kaolin was $440 \mathrm{mg} / \mathrm{l}$.

\section{Flocculation}

The model wastewater was flocculated by the organic Sokoflok 56A polymer flocculant (medium anionity, $0.1 \%$ wt. aqueous solution; flocculant weight per flocculant solution volume $m_{F} / V_{F}=$ $1 \mathrm{mg} / \mathrm{ml}$; Sokoflok Ltd., Czech Republic). The experimental conditions are specified in Table 3. The flocculation was initiated by adding flocculant into the agitated vessel, and the flocculation time measurement was started.

\section{Image acquisition}

After impeller shutdown, the flocks began to settle. During sedimentation, the images of flocks passing through the illuminated plane and having 10-bit depth were captured at frame rate $10 \mathrm{~s}^{-1}$, exposure $=5 \mathrm{~ms}$, and gain $35 \mathrm{~dB}$. Image capturing started $20 \mathrm{~s}$ after impeller shutdown and took 120 s. Finally 1200 images were obtained for the flocculation experiment and some were stored in a hard disk in 24-bit jpg format.

\section{Image analysis}

The images were analyzed using SigmaScan software and its pre-defined filters (filter No. 8 for removing one-pixel points, filter No. 10 for removal of objects touching on an image border, and filter No. 11 for filling an empty space in identified objects caused by capture error) and our macros (Svačina [7] in detail). 
Table 4: Generalized correlation $\Delta\left(1 / d_{f e q}\right)^{*}=f\left(\Delta\left[n t_{F}\right]_{\log }^{*}\right)$ : parameters fitted

\begin{tabular}{|c|c|c|c|c|c|c|c|}
\hline$\varepsilon_{V}$ & $\mathrm{n}$ & {$\left[n t_{F}\right]_{\max }$} & $t_{F_{\max }}$ & $d_{f e q_{\max }}$ & $A_{f}^{*}$ & $I_{y x}$ & $\delta_{r_{a v e}} / \delta_{r_{\max }} * 1$ \\
\hline$\left(\mathrm{W} / \mathrm{m}^{3}\right)$ & $($ ot $/ \mathrm{min})$ & $(-)$ & $(\min )$ & $(\mathrm{mm})$ & $(-)$ & $(-)$ & $(\%)$ \\
\hline 40 & 180 & 1440 & 8 & 1.4062 & 16.373 & 0.8952 & $2.5 / 4.4^{* 2}$ \\
\hline
\end{tabular}

Note: ${ }^{* 1}$ Relative error of equivalent flock size $d_{f e q}$ : average/maximum absolute value.

Note: ${ }^{* 2}$ Flock size for $n t_{F}=3600$ was excluded from the evaluation.

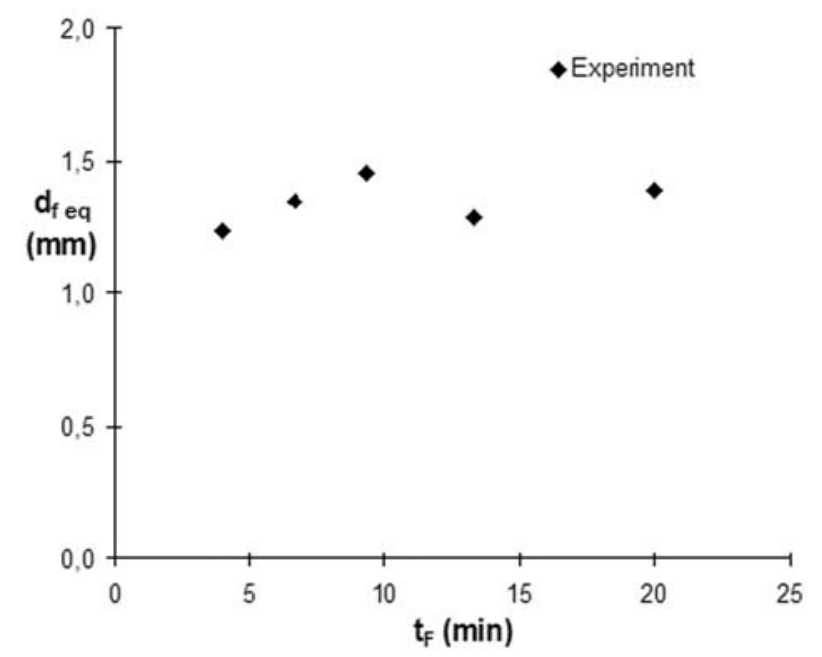

Fig. 3: Experimental data - Maximum flock size vs. flocculation time $-d_{f e q}=f\left(t_{F}\right)$

\subsection{Experimental data evaluation}

From the images that were captured, the largest flock was identified and its projected area was determined for the given flocculation time. The equivalent diameter calculated according to the flock area plotted in dependence on the flocculation time for a given flocculant dosage and mixing intensity is shown in Fig. 3. When flocculation time increases, the flock size increases up to the maximum value, due to primary aggregation, and then decreases due to flock breaking.

\section{Generalized correlation}

$\Delta\left(1 / d_{f e q}\right)^{*}=f\left(\Delta\left[n t_{F}\right]_{\text {log }}^{*}\right)$

The dependence of calculated equivalent diameter $d_{f e q}$ on flocculation time was fitted according to the generalized correlation (12). The generalized correlation parameters are presented in Table 4. A comparison of the experimental data and the generalized correlation is depicted in Fig. 4.

\section{Fractal dimension}

The flocks generated are often porous and have an irregular shape, which complicates the design of the floc-

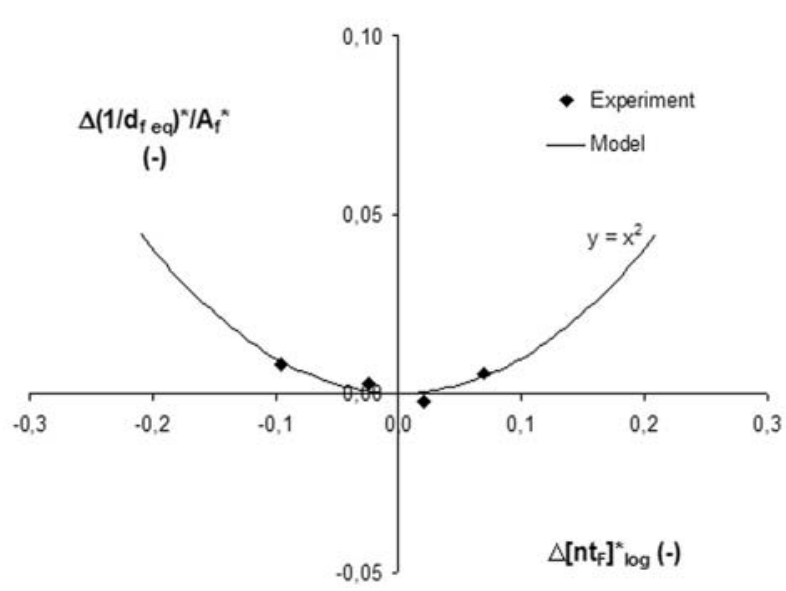

Fig. 4: Generalized correlation $\Delta\left(1 / d_{f e q}\right)^{*}=f\left(\Delta\left[n t_{F}\right]_{l o g}^{*}\right)$

culation process. Fractal geometry is a method that can be used for describing the properties of irregular objects. Some flock properties such as shape, density, sedimentation velocity can be described on the basis of fractal geometry. A fractal dimension of the $3^{\text {rd }}$ order $D_{f 3}$ evaluated from the flock mass was usually determined. Since in our case we measured the projected area of the flocks, the fractal dimension of the $2^{\text {nd }}$ order $D_{f 2}$ was used for flock shape characterization. The relation among projected area $A$, characteristic length scale $L_{c h a r}$ and fractal dimension $D_{f 2}$ is given by:

$$
A=C \cdot L_{\text {char }}^{D_{f 2}}
$$

The largest flocks determined in the images were used for fractal dimension estimation. The maximum flock size was used as a characteristic length scale. The fractal dimension $D_{f 2}$ was determined for each flocculation time. For illustration, the dependence of the projected area on the maximum flock size is shown in Fig. 5 for dimensionless flocculation time $n t_{F}=1680$. The fractal dimension $D_{f 2}$ plotted in dependence on flocculation time for a given flocculant dosage and mixing intensity is shown in Fig. 6. 


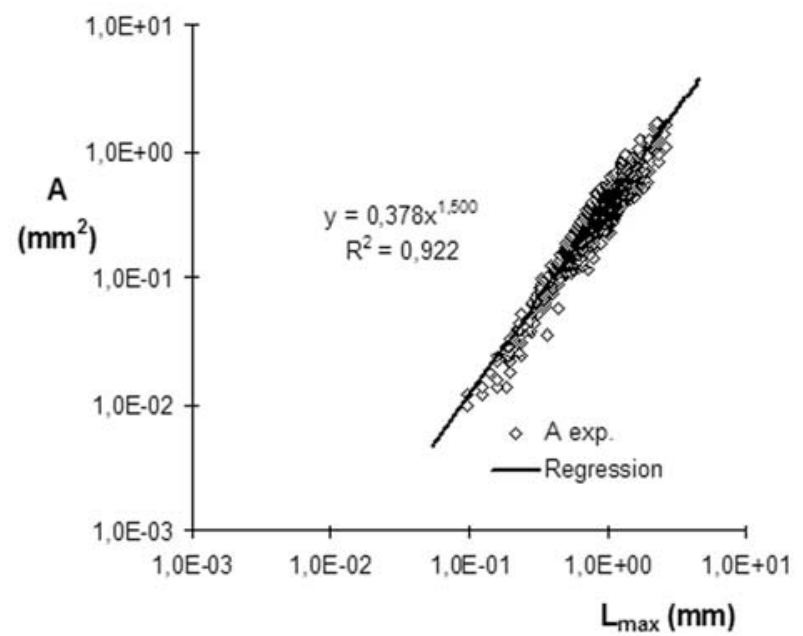

Fig. 5: Fractal dimension determination - example for $n t_{F}=1680$

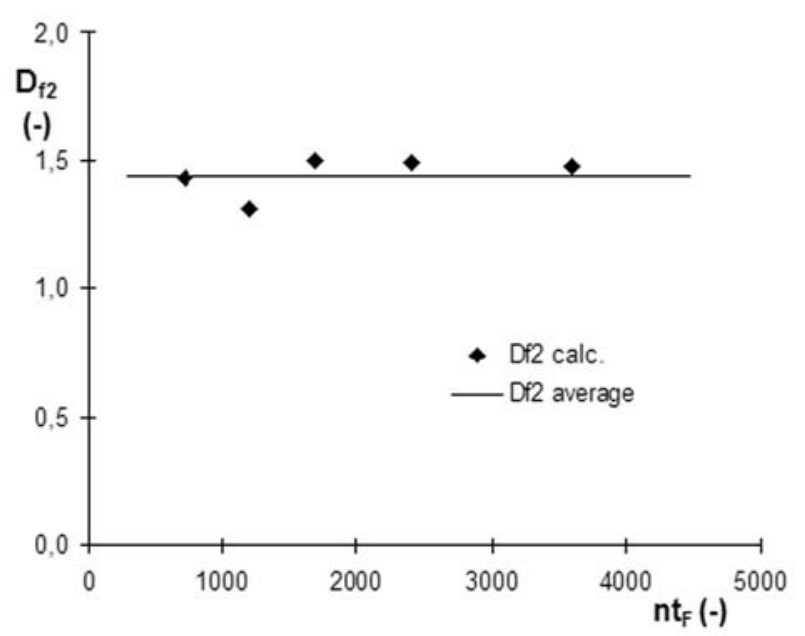

Fig. 6: Fractal dimension vs. dimensionless flocculation time $-D_{f 2}=f\left(n t_{F}\right)$

Table 5: Fractal dimension - hypothesis testing

\begin{tabular}{|c|c|c|c|c|}
\hline$\varepsilon_{V}$ & $m$ & $t$-distribution & Relation & $\begin{array}{c}t \text {-characteristics }|t| \\
D_{f 2}=B \cdot\left(n t_{F}\right)^{\beta}\end{array}$ \\
$\left(\mathrm{W} / \mathrm{m}^{3}\right)$ & $(-)$ & $t_{(m-2), \alpha=0.05}$ & $\beta_{\text {calc }}$ & $\begin{array}{c}\text { Hypothesis } \\
D_{2}=B \cdot\left(n t_{F}\right)^{0} \\
\beta_{\text {pred }}=0\end{array}$ \\
\hline 40 & 5 & 3.1825 & 0.045 & $0.97($ Yes $)$ \\
\hline
\end{tabular}

Note: The absolute value of parameter $t$ is presented in brackets.

Note: The $t$-distribution for $(m-2)$ degrees of freedom and significance level $\alpha=0.05$.

The effect of flocculation time on fractal dimension $D_{f 2}$ was tested by hypothesis testing. The statistical method of hypothesis testing can estimate whether the differences between the parameter values predicted (e.g. by some proposed theory) and the parameter values evaluated from the measured data are negligible. In this case, we assumed the dependence of fractal dimension $D_{f 2}$ on dimensionless flocculation time, described by the simple power law $D_{f 2}=B \cdot\left(n t_{F}\right)^{\beta}$, and the difference between predicted exponent $\beta_{\text {pred }}$ and evaluated exponent $\beta_{\text {calc }}$ was tested. The hypothesis test characteristics are given as $t=\left(\beta_{\text {calc }}-\beta_{\text {pred }}\right) / s_{\beta}$ where $s_{\beta}$ is standard error of parameter $\beta_{\text {calc }}$. If the calculated $|t|$ value is less than the critical value of the $t$-distribution for $(m-2)$ degrees of freedom and significance level $\alpha$, the difference between $\beta_{\text {calc }}$ and $\beta_{\text {calc }}$ is statistically negligible (statisticians state: "the hypothesis cannot be rejected"). The hypothesis test result and parameter $\beta$ evaluated from the data is presented in Table 5. The fractal dimension was found to be independent of the flocculation time, and the value $D_{f 2}=1.442 \pm 0.12$ was determined as an average value.

\section{Conclusions}

The following results have been obtained:

- A simple semiempirical generalized correlation for flock growth kinetics has been proposed.

- A generalized correlation has been successfully tested and verified, using published data from Kilander et al. (2007). The generalized correlation parameters are presented in Table 1. A comparison of the experimental data and the generalized correlation is depicted in Fig. 1.

- The flock growth kinetics was investigated in a baffled tank agitated by a Rushton turbine at mixing intensity $40 \mathrm{~W} / \mathrm{m}^{3}$ and kaolin concentration $0.44 \mathrm{~g} / \mathrm{l}$. The flock size and flock shape were investigated by image analysis.

- The tests were carried out on the kaolin slurry model wastewater. The model wastewater was flocculated with organic Sokoflok 56A flocculant (solution $0.1 \%$ wt.). 
- The largest flock was identified from the images, and its projected area was determined for a given flocculation time. The calculated equivalent diameter plotted in dependence on flocculation time for the given flocculant dosage and mixing intensity is shown in Fig. 3.

- The flock size increases with increasing flocculation time up to a maximum value due to primary aggregation, and then decreases due to flock breaking.

- The proposed simple semiempirical generalized correlation for flock growth kinetics was used for data treatment. The model parameters are presented in Table 4.

- The fractal dimension $D_{f 2}$ was determined for each flocculation time on the basis of the experimental data. Using the statistical hypothesis test, the fractal dimension was found independent of flocculation time, and the value $D_{f 2}=1.442 \pm 0.125$ was determined as the average value.

\section{Acknowledgement}

This research has been supported by The Grant Agency of Czech Republic project No. 101/07/P456 "Intensification of Flocculation in Wastewater Treatment".

\section{References}

[1] Sulc, R.: Flocculation in a Turbulent Stirred Vessel. PhD. thesis. Czech Technical University, Faculty of Mechanical Engineering, 2003 (in Czech).

[2] Šulc, R., Ditl, P.: Effect of Mixing on Flocculation Kinetics. In: Proceedings of $14^{\text {th }}$ Interna- tional Congress of Chemical and Process Engineering CHISA 2000, (CD ROM), Prague, 2000.

[3] Šulc, R., Ditl, P.: The Effect of Flocculant Dosage on the Flocculation Kinetics of Kaolin Slurry in a Vessel Agitated by Rushton Turbine at Mixing Intensity $168 \mathrm{~W} / \mathrm{m}^{3}$ and Kaolin Concentration $0.58 \mathrm{~g} / \mathrm{l}$. Czasopismo Techniczne - Seria: MECHANIKA, Vol. 105 (2008), pp. 341-349.

[4] Kilander, J., Blomström, S., Rasmuson, A.: Scale-up Behaviour in Stirred Square Flocculation Tanks. Chem. Eng. Sci., Vol. 62 (2007), pp. $1606-1618$.

[5] Kysela, B., Ditl, P.: The Measurement of Floc Size and Flocculation Kinetics by the Laser Knife and Digital Camera. In: Proceedings of 16th International Congress of Chemical and Process Engineering CHISA 2004, (CD-ROM), Prague, 2004, ISBN 80-86059-40-5.

[6] Kysela, B., Ditl, P.: Floc Size Measurement by the Laser Knife and Digital Camera in an Agitated Vessel. Inzynieria Chemiczna i Procesowa, Vol. 26 (2005), pp. 461-468.

[7] Svačina, O.: Application of Image Analysis for Flocculation Process Monitoring. Diploma Project. Czech Technical University, Faculty of Mechanical Engineering, 2009 (in Czech).

Ing. Radek Šulc, Ph.D.

Phone: 420224352 558, Fax: +420224 310292

E-mail: Radek.Sulc@fs.cvut.cz

Department of Process Engineering,

Faculty of Mechanical Engineering,

Czech Technical University in Prague,

Technická 4, 16607 Prague, Czech Republic

\section{Notation}

$A \quad$ flock area projected

$A_{f}^{*} \quad$ coefficient; model parameter (12)

$A_{Z r^{*}}^{*} \quad$ residual turbidity shift; model parameter (4)

$d_{f e q} \quad$ equivalent flock diameter according to flock area

$-$

$d_{f} \quad$ flock size

$\mathrm{mm}$

$d_{f_{\max }} \quad$ maximum flock size; model parameter (12)

$\mathrm{mm}$

$D$

tank diameter

$\mathrm{mm}$

$D_{F}$

flocculant dosage

$\mathrm{m}$

fractal dimension of $2^{\text {nd }}$ order

$\mathrm{ml} / \mathrm{l}$

$D_{f 2}$

correlation index

$I_{y x}$

characteristic length scale

$-$

$L_{\text {char }}$ impeller rotational speed

$\mathrm{mm}$ 
$\left[n t_{F}\right]_{\min } \quad$ model parameter (4)

$\left[n t_{F}\right]_{\max } \quad$ model parameter (12)

$t$

hypothesis test characteristics

$t_{F} \quad$ flocculation time

minute

$t_{(m-2), \alpha} \quad$ critical value of $t$-distribution for $(m-2)$ degrees of freedom and significance level $\alpha$

$t_{\text {sed }} \quad$ sedimentation time

$Z_{0} \quad$ turbidity before flocculation

minute

$Z_{r} \quad$ residual turbidity after flocculation

FAU

$Z_{e}^{*} \quad$ turbidity removal degree

$Z_{r}^{*} \quad$ residual turbidity degree

$Z_{r_{\min }}^{*} \quad$ model parameter (4)

Greek letters

$\delta_{r} \quad$ relative error;

$\delta_{r}=100^{*}$ (experimental value - regression value)/regression value

$\Delta\left(1 / d_{f}\right)^{*} \quad$ variable

$\Delta\left[n t_{F}\right]_{\log }^{*}$ variable

$\Delta Z_{r}^{*} \quad$ variable

$\varepsilon_{V} \quad$ specific impeller power input (per volume unit)

$\mathrm{W} / \mathrm{m}^{3}$

Indices

* dimensionless

$* \cdot x \quad$ link

ave average

$\max \quad$ maximum

min minimum 